ROBERTO DA ROCHA LIMA

CONSTRUÇÃO DE EQUIPAMENTO DE PLASMA PARA OBTENÇÃO DE FILMES FINOS E COMPÓSITOS ÚTEIS NA FABRICAÇÃO DE SENSORES 
ROBERTO DA ROCHA LIMA

\title{
CONSTRUÇÃO DE EQUIPAMENTO DE PLASMA PARA OBTENÇÃO DE FILMES FINOS E COMPÓSITOS ÚTEIS NA FABRICAÇÃO DE SENSORES
}

\author{
Tese apresentada à Escola \\ Politécnica da Universidade de \\ São Paulo para a obtenção do \\ título de Doutor em Engenharia.
}




\section{CONSTRUÇÃO DE EQUIPAMENTO DE PLASMA PARA OBTENÇÃO DE FILMES FINOS E COMPÓSITOS ÚTEIS NA FABRICAÇÃO DE SENSORES}

Tese apresentada à Escola Politécnica da Universidade de São Paulo para a obtenção do título de Doutor em Engenharia.

Área de concentração:

Engenharia Elétrica

Orientadora:

Prof ${ }^{a}$. Dr ${ }^{a}$. Maria Lúcia Pereira da Silva 
Dedico este trabalho a

Memória de Germino da Rocha Lima. Um pai batalhador, muito amado e querido por todos seus entes.

Minha maravilhosa família: Ignês (mãe), meus irmãos: Eng. Jorge, Prof $^{\mathrm{a}}$. Marina, Joelma e minha querida sobrinha Acácia Karoline. Uma família que sempre muito unida em todos os momentos me apoiou para tornar esse sonho uma realidade. 
À Juliana, pelos momentos de felicidade além do incentivo, sempre com muito carinho. 


\section{AGRADECIMENTOS}

Uma tese de Doutorado jamais será um trabalho isolado de seu autor ao longo das madrugadas e finais de semana. Ela depende de um conjunto de profissionais em áreas correlatas que reconhecem a sua importância e são capazes de transformar as inúmeras dificuldades em realidade. Por isso eu expresso os meus sinceros agradecimentos a cada um desses profissionais.

Agradeço,

desde já peço perdão e ao mesmo tempo agradeço as pessoas que esqueci de citar; pois foram tantas as que contribuíram para desenvolvimento desse trabalho.

a minha orientadora Profa. Dra. Maria Lúcia Pereira da Silva, pela orientação, por ter acreditado e confiado na minha aspiração para a realização deste trabalho, por seus constantes estímulos, transmitido durante todo o percurso desse trabalho e pela amizade.

ao Prof. Dr. José A. S. da Matta, pela amizade, ensinamentos de física de plasmas; contribuições iniciais na pesquisa e por sempre estar disposto a discutir sobre as melhorias do equipamento.

aos Engs. Ablício, Nelson Cuevas e Tec. Eduardo Monteiro, pelos trabalhos técnicos; pela boa vontade que sempre me foi dispensada em sugestões, ensinamentos de eletro-eletrônica e sobretudo por suas amizades.

ao Dr. Estevão (Porto Rico), Nelson Ordonez, Alexandre (Leleu) e Adir pela boa vontade que sempre me foi dispensada em sugestões e pelas análises de XPS, AFM, SEM, etc. e colaborações.

aos amigos do IFUSP: Pedro, Marcos, Otávio, Sr. Donato, Betão, Wilson, Alex, Celso Peregro, José Carlos de Abreu pelo profissionalismo, na boa vontade na execução dos trabalhos, pelas sugestões para a melhoria do equipamento e pelo bom humor do dia-a-dia.

ao Prof. Dr. Marcos Nogueira Martins, por ter me dado a oportunidade de construir este equipamento utilizando a infra-estrutura do Laboratório do Acelerador Linear do IFUSP.

aos Prof. Dr. Jiro Takahashi, Luciano Portante, Marcelo Lucena e a todos os outros companheiros de trabalho do Laboratório do Acelerador Linear, pela amizade, trabalhos técnicos, companheirismo e colaboração na construção do equipamento de plasma.

aos amigos de Happy hour de sexta-feira pela descontração e troca de conhecimentos os mais inusitados possíveis.

às parcerias: Universidade de Porto Rico, Instituto de Física e LSI(EPUSP).

aos amigos e companheiros do grupo: Alexsander, Rodrigo, Antonio Filho, Lilian, Leonardo e a todos os estudantes de iniciação científica (Rodolfo, Hélio, José Fábio, Caio, Eduardo Matsuy, etc) que passaram pelo grupo e deram suas contribuições.

a todos os professores, mestres e orientadores de minha carreira acadêmica a quem tive a honra de ter sido aluno e orientado. Através de seus ensinamentos, mais um sonho foi realizável.

À FAPESP e CNPq pelo apoio financeiro.

À São Judas Tadeu! Minha fé em Deus sempre foi intercedida pela sua graça. 